\title{
LEISURE ACTIVITIES OF THE POPULATION OF MONTENEGRO
}

\author{
DJUKANOVIC Borislav ${ }^{1}$, MACANOVIC Nebojsa ${ }^{2}$, RADOVIC-MARKOVIC Mirjana ${ }^{3}$ \\ ${ }^{I}$ Faculty of Humanities studies, Podgorica (MONTENEGRO) \\ ${ }^{2}$ Faculty of Philosophy, Banja Luka (BOSNIA AND HERZEGOVINA) \\ ${ }^{3}$ Faculty of Business Economics and Entrepreneurship, Belgrade (SERBIA) \\ E-mails:borivoje.djukanovic@gmail.com; macanovicn@yahoo.com; mirjana.radovic@ien.bg.ac.rs
}

\begin{abstract}
In this paper, we examined the choice of types of favorite and unpopular activities and ways of practicing among different groups, age, education, and strata of Montenegrin society in leisure time. A random selection of 805 respondents was made. A special questionnaire was constructed for the purposes of this research. The starting theoretical position was Bourdieu's theory. The three favorite activities of our respondents in their free time were watching television, hanging out with friends, and walking. It is interesting that sleep is in the fourth place in terms of frequency in the first two choices of the most favorite activities, and in the third choice even in the second place. We can conclude that great poverty was observed in the choice of three activities that the respondents most often perform in the order of their importance. However, almost 2/5 (39\%) practice them actively. It seems that these restrictions in terms of frequency are more conditioned by external, objective factors than the poverty of the respondents' needs for various forms of leisure recreation. The results of our research largely confirm Bourdieu's theoretical heritage, and partly do not confirm it. The most unexpected result is a very slight layer difference in the choice of the most favorite activity and the absence of differences in stating the reasons for the least popular. In our opinion, the main reason should not be sought in the epistemological weaknesses of Bourdieu's theory, but in the fact that Bourdieu's theory can be empirically tested on developed societies so that differences can be clearly expressed, in "pure" form. At least now, Montenegrin society does not belong to such societies.
\end{abstract}

Keywords: leisure, activities, Bourdieu, gender, age, education, layer

JEL: $P 23$

DOI: 10.5937/intrev2103142D

UDC: $316.728(497.16)$

379.8:316.023(497.16)

COBISS.SR-ID 55159305 


\section{INTRODUCTION}

Leisure time is the area of everyday life in which personality individuality, personal affinities and tastes are expressed in the most complete way. In free time, the personality is the least limited by external obstacles. That is why free time is the part of cultural consumption in which the creativity of a person is most pronounced. The new information society exposes new challenges to the education system, since intellect and creativity have become the main productive and creative force of civilization[14].He rightly points out that after examining musical tastes, leisure is the area in which various aspects of cultural consumption can be most fully understood[1][2]. Therefore, practices and tastes in leisure are an important area of social life to test Bourdieu's theory, from which we started in this paper[3][4][5][6][7] [8][9][10][11][12].

\section{METHOD}

A randomly selected sample for this research consists of 805 respondents from three regions of Montenegro and Podgorica. In this paper, which is exploratory in nature, we wanted to examine the types of activities that Montenegrins most often engage in leisure time, and then whether there are gender, age, education and stratum - class differences in leisure time. For the purposes of this research, we constructed a special questionnaire that contains questions about the type of activities that respondents most often use in their free time, as well as which activities they consider the most and least favorite. The activities were ranked according to the degree of popularity, ie dislike, and then we examined whether there are statistically significant differences by gender and other listed socio - demographic characteristics.

\section{RESULTS}

Table 1 shows that the respondents perform different activities. However, it is noticeable that three dominate: watching TV, walking, and hanging out with friends. This indicates a considerable stereotype of spending free time, which is also an important indicator of a relatively low quality of life. When asked whether they dedicate as much time as they would like to their favorite leisure activity, $535(67.3 \%)$ answered in the affirmative, and 260 (32.7\%) in the negative. Somewhat later, we will present the reasons that the respondents state by gender and other socio-demographic characteristics. 
Table1. Activities that respondents most often do in their free time.

\begin{tabular}{|c|c|c|c|c|}
\hline & $\mathrm{N}$ & Percent & Valid percentage & $\begin{array}{l}\text { Cumulative } \\
\text { percentage }\end{array}$ \\
\hline Watching TV & 176 & 21.9 & 21.9 & 21.9 \\
\hline Walk & 141 & 17.5 & 17.6 & 39.5 \\
\hline Sleeping, lounging, napping & 54 & 6.7 & 6.7 & 46.2 \\
\hline Going to the cinema & 17 & 2.1 & 2.1 & 48.3 \\
\hline Newspaper reading & 18 & 2.2 & 2.2 & 50.6 \\
\hline Socializing with friends & 117 & 14.5 & 14.6 & 65.1 \\
\hline Socializing with relatives & 21 & 2.6 & 2.6 & 67.7 \\
\hline Going to the theater & 4 & 0.5 & 0.5 & 68.2 \\
\hline Shopping & 18 & 2.2 & 2.2 & 70.5 \\
\hline Playing sports and recreation & 26 & 3.2 & 3.2 & 73.7 \\
\hline Restaurants & 14 & 1.7 & 1.7 & 75.5 \\
\hline Reading books & 31 & 3.9 & 3.9 & 79.3 \\
\hline Going out to a café & 23 & 2.9 & 2.9 & 82.2 \\
\hline Home decoration and flower care & 24 & 3.0 & 3.0 & 85.2 \\
\hline Handicrafts, and similar hobbies & 21 & 2.6 & 2.6 & 87.8 \\
\hline Going out to a disco or club & 1 & 0.1 & 0.1 & 87.9 \\
\hline Additional education and training (attending various courses, reading professional literature) & 9 & 1.1 & 1.1 & 89.0 \\
\hline Preparation of culinary specialties & 16 & 2.0 & 2.0 & 91.0 \\
\hline Bookmaker and other games of chance & 5 & 0.6 & 0.6 & 91.7 \\
\hline Fishing & 24 & 3.0 & 3.0 & 94.6 \\
\hline Going to the football match & 13 & 1.6 & 1.6 & 96.3 \\
\hline Excursions & 12 & 1.5 & 1.5 & 97.8 \\
\hline Watching movies on video, DVD, computer & 6 & 0.7 & 0.7 & 98.5 \\
\hline Playing computer games & 12 & 1.5 & 1.5 & 100.0 \\
\hline Total: & 803 & 99.8 & 100.0 & \\
\hline Unknown & 2 & 0.2 & & \\
\hline TOTAL & 805 & 100.0 & & \\
\hline
\end{tabular}

\section{Source: Authors}

We were also interested in how the respondents ranked the activities according to the importance they attached to them (Table 2). It is interesting that sleep is in the fourth place in terms of frequency in the first two choices of the most favorite leisure activities, and in the third choice even in the second place (Table 2).

Table 2. Three leisure activities in the first, second and third choice in order of importance

\begin{tabular}{|l|l|l|l|}
\hline & Choices & Choices & Choices \\
\hline Activities & First & Second & Third \\
\hline Watching TV & $176(21.9 \%)$ & $74(9.2 \%)$ & $53(6.6 \%)$ \\
\hline Contacts with friends & $117(14.8 \%)$ & $119(14.8 \%)$ & $97(12.1 \%)$ \\
\hline Walk & $141(17.5 \%)$ & $114(14.2 \%)$ & $64(8.0 \%)$ \\
\hline Sleep & $54(6.7 \%$ & $50(6.2 \%)$ & $69(8.6 \%)$ \\
\hline
\end{tabular}

Source: Authors

The first most important choice is to watch television. The other two in terms of frequency in the first choice are walking and hanging out with friends (Table 2). In the second choice, hanging out with friends is in the first place, walking in the second place, and watching television in the third place. In the third choice, hanging out with friends is in the first place, sleeping in the second, and walking in the third. Since the basic categories of answers in the three choices are repeated and intertwine, we will compare the respondents according to the basic socio - demographic characteristics only according to the first choice. Despite the pronounced stereotypes, some choices about spending free time basically have a positive side, and it is reflected in the frequency of spending time with friends. These basically collectivist patterns play an important role in psychologically resisting anomic moods. The stereotyping of the three most desirable choices of leisure activities is conditioned by financial problems. When they are not limited by external circumstances, respondents show greater motivation to actively engage in leisure activities. A more important question is not the type of cultural content that is consumed but also what kind of attitude users have towards them [13]. Activity implies selectivity and built tastes of cultural consumption, and therefore there are attitudes that this division into active and passive cultural consumption is more relevant today than the division into high and low culture [8]. Based on the inclusion of several classification criteria, such as whether the decision to opt for a leisure activity implies a conscious, personal decision of the subject, whether it involves a certain effort to start a certain activity, whether it is a mental or physical 
effort, etc. Professor Spasić presented an acceptable three-level classification: passive, transient and active [8]. Passive forms of leisure include: watching TV, sleeping and reading newspapers. In the "transitional": hanging out with friends, hanging out with relatives, going to cafes, reading books, going to a cafe, betting, going to a game, watching movies on video, playing computer games. The active ones include: walking, going to the cinema, going to the theater, shopping, playing sports, decorating the home, handicrafts and hobbies, going to a disco, additional education, preparing culinary specialties, fishing, going on a trip[8].

Table 3. The percentage frequencies and percentage structures for three degrees - from passive to active leisure time.

\begin{tabular}{|l|l|l|l|l|}
\hline $\begin{array}{l}\text { Passive, } \\
\text { transitional, } \\
\text { and active } \\
\text { leisure time }\end{array}$ & $\mathrm{N}$ & & & \\
\hline Passive & 248 & Percent & Valid Percentage & Cumulative Percentage \\
Transitional & 242 & 30.8 & 30.9 & 30.9 \\
Active & 313 & 30.1 & 30.1 & 61.0 \\
Total: & 803 & 38.9 & 39.0 & 100.0 \\
Unknown & 2 & 99.8 & 100.0 & \\
TOTAL: & 805 & 0.2 & & \\
\hline
\end{tabular}

Source: Authors

Respondents are more willing to spend their free time in a somewhat more active way than when it comes to choosing activities, because almost $40 \%$ of respondents spend their free time in an active, and almost a third in both active and passive way (Table 3.). This can be explained by the fact that the way of using free time is less dependent on available material and time resources than the choice of types of activities.

\section{INDICATORS OF LEISURE USE ACCORDING TO SOCIO-DEMOGRAPHIC CHARACTERISTICS}

Gender: Statistically significant differences were found between the sexes in terms of choosing the most favorite leisure activity according to the first choice $(\mathrm{X} 2=23.531$; $\mathrm{df}=6$; $\mathrm{p}<0.005)$. women significantly more. In addition, men emphasize sleep, laziness, and women significantly less often as their favorite leisure activity. Interestingly, both spouses choose the most unpopular activities as the ones they prefer to the other partner $(\mathrm{X} 2=122,334 ; \mathrm{df}=22 ; \mathrm{p}=0,000)$. Men do not like going to the theater, shopping, reading books, going to cafes, beautifying and nurturing the interior of the apartment-house, handicrafts, making culinary specialties, and women do not like going to cafes, cafes, more than men. bookmakers and games of chance and going to first choice matches. The main reasons why they fail to devote their free time to their favorite activities for men are lack of time because they must dedicate that free time to earning, and women because they have to dedicate that free time to family responsibilities and household chores $(\mathrm{X} 2=29,382 ; \mathrm{df}=5 ; \mathrm{p}=0.000)$. There is a statistically significant correlation between gender and active or passive use of free time in the first choice; women significantly more often use free time in an active way than men $(\mathrm{X} 2=9.323, \mathrm{df}=1, \mathrm{p}<0.002)$. Overall, according to the available resources, women use their free time in a more meaningful, richer way and more actively than men. They have significantly more pronounced tastes and show preferences towards acquiring cultural capital more than men. Age There are statistically significant differences between the different ages in terms of the most favorite leisure activity in the first choice (X2 $=38.233$; $\mathrm{df}=6 ; \mathrm{p}<0.000)$.

Young people under the age of 30 are significantly less likely to watch television as their favorite activity, and those over the age of 51 are significantly more likely. When it comes to hanging out with friends, the situation is reversed. Respondents over the age of 50 and older cite significantly more than expected frequencies as the most unpopular activity in the first choice, sleep, lounging, etc., and those younger than 30 cite reading newspapers as the most unpopular in the first choice. Old and young do not differ statistically in the reasons for not fulfilling their favorite activities to the extent that they would like to. Younger people use their free time significantly more actively than older people $(\mathrm{X} 2=23,668$; $\mathrm{df}=2$; $\mathrm{p}<0.000$ ), but only in the first choice, while in the second and third choice these differences are not statistically significant. Surprising is the great intellectual passivity of young people under 30 who least want to dedicate part of their free time to professional education and training and are not even motivated to read newspapers in their free time. On the other hand, he encourages those over the age of 50 to need 
more meaningful and active leisure time, because in the first choice they emphasize that they want to sleep at least in their free time and hazelnuts, and in the second least unpopular activities are cooking culinary specialties and reading newspapers.

Education: The low-educated as their favorite leisure activity significantly more often watch television, and the highly educated significantly less often $(\mathrm{X} 2=18.718$; $\mathrm{df}=6 ; \mathrm{p}<0.005)$. The low-educated are significantly more likely to point out that they cannot afford the desired activities in their free time $(\mathrm{X} 2$ test $=$ 34,964; $\mathrm{df}=10 ; \mathrm{p}<0,000)$. There is a statistically significant correlation between education and the most unpopular activities in the first choice $(\mathrm{X} 2=84.87 ; \mathrm{df}=44 ; \mathrm{p}<0.000)$. When it comes to the most unpopular activity towards education, it can be noticed that the low-educated reject gambling significantly less than the secondary and higher-educated. Highly educated people consider fishing to be the most unpopular activity significantly higher than expected. The highly educated spend their free time significantly less passively, and the low-educated spend significantly more $(\mathrm{X} 2=19.903$; $\mathrm{df}=4 ; \mathrm{p}=0.001)$. These results confirm Bourdieu's theory of educational differences in the choices of the Montenegrin population in leisure time [3][4]. Layer Layers differ slightly in the choice of the most favorite leisure activity $(\mathrm{X} 2=32.558 ; \mathrm{df}=21 ; \mathrm{p}<0.051$, at the limit of significance). Experts more often choose walking as their favorite leisure activity, and unskilled worker and semi-skilled workers significantly less often. No statistically significant differences were found between the layers in terms of the reasons why they cannot afford the most popular activities to the desired extent, and also in terms of the most favored activities. Professionals spend their free time significantly more actively, and unskilled workers and semi-skilled workers significantly more often passively No statistically significant differences were found among the strata in the selection of the most unpopular activities. According to the degree of activity in free time, the layers differ significantly $(X 2=30.802 ; \mathrm{df}=14 ; \mathrm{p}=0.00 \mathrm{o})$. Experts spend their free time significantly more actively, and unskilled workers and semi-skilled workers significantly more often passively.

At the end of this block of questions, we were especially interested in what the respondents prefer to have a dialogue with close people in their free time. 16 topics were offered. We made an index of three ranks for the three most favorite topics of dialogue of respondents with close people in their free time, by weighting the ranks: the first rank got three points, the second rank two points and the third rank one point. We got the following sequence of favorite topics in our free time: first: sports - 37.99\%; others: children 31.68\%; third: political events in Montenegro - 30.31\% Statistically significant differences were found by gender; sports are the most popular topic for men and children for women $(\mathrm{U}=59721,500 \mathrm{p}<0.000)$. It is interesting that with age, the importance of sports decreases as the most favorite topic in conversations with friends and friends in free time $(\operatorname{Ro}=0.178 ; p<0.000)$. $; p<0.000)$. It is interesting to note that the order of topics and their importance is not related to education. Does that mean that sports and politics are the most universal topics, and in the modern age more and more the future of children, who are therefore not affected by the educational status of the respondents, it is difficult to say?! Negative correlations were found on the first question; the lower the class and the class, the more significantly the favorite topic of conversation for leisure time and vice versa $(\mathrm{Ro}=0.107 ; \mathrm{p}<0.002)$.

\section{CONCLUSION}

The three favorite activities of our respondents in their free time were watching television, hanging out with friends and walking. It is interesting that sleep is in the fourth place in terms of frequency in the first two choices of the most favorite activities, and in the third choice even in the second place. We can conclude that great poverty was observed in the choice of three activities that the respondents most often perform in the order of their importance. However, almost 2/5 (39\%) practice them actively. It seems that these frequency restrictions are more conditioned by external, objective factors than the poverty of the respondents' needs for various forms of leisure recreation. Limited, modest resources influence a certain averaging of the choice of activities of respondents of different age, educational and stratum categories, especially in the second and third rank. We expected that the differences between the young and the old would be more pronounced, and especially the layered differences. Let us remember that the layers differ only slightly in the choice of the most favorite activity, while they do not differ in the reasons for the impossibility of practicing the most unpopular activity. activities that respondents practice in their free time, but also because of certain male - female stereotypes about what are the subjects of gender interest. The only consistent difference is by gender, and they are completely in the spirit of Bourdieu's theory. The 
results of our research largely confirm Bourdieu's theoretical heritage, and partly do not confirm it. The most unexpected result is a very slight layer difference in the choice of the most favorite activity and the absence of differences in stating the reasons for the least popular. In our opinion, the main reason should not be sought in the epistemological weaknesses of Bourdieu's theory, but in the fact that Bourdieu's theory can be empirically tested on developed societies so that differences can be clearly expressed, in "pure" form. At least now, Montenegrin society does not belong to such societies.

\section{REFERENCES}

[1] Lizardo, O.(2006) “The Puzzle of Women's Highbrow Culture Consumption: Integrating Gender and Work into Bourdieu's Class Theory of Taste.” Poetics 34:1-23. Čigoja štampa i ISIF, Beograd.

[2] Radović - Marković, M. , Salamazdeh, A. (2011), Critical Approach towards the Employment Analysis in Theory Methodology and Research. Y: Influence of the Humanities and Social Sciences on Business and Societal Change: Conference Proceedings. Vilnus, Lithuania: Naujosios Kartos Mokslo ir Verslo Klasteris, 2011, str.156-166. [COBISS.SR-ID 512164962]

[3] Bourdieu,P. and Passeron, J. (1977) Reproduction in Education,Society and Culture. London: Sage

[4] Bourdieu P (1987) What makes a social class. Berkeley Journal of Sociology 32: 1-18.

[5]P (1990) In Other Words: Essays towards a Reflexive Sociology. Stanford, CA: Stanford University Press.

[6] Bourdieu P (1997) Language and Symbolic Power. Cambridge: Polity. Bourdieu P (1998) The myth of globalization and the European welfare state. In: Bourdieu P Acts of Resistance. Cambridge: Polity, 29-44.

[7] Bourdieu P (1998) The myth of globalization and the European welfare state. In: Bourdieu P Acts of Resistance. Cambridge: Polity, 29-44.

[8] Spasić, I. (2004) Sociologija svakodnevnog života. Zavod za udžbenike i nastavna sredstva, Beograd

[9] Bourdieu,P. (2013) Distinkcija. Društvena kritika suda. CID,Podgorica

[10] Krumov , K., Kamenova, M., Radović-Marković, M.,(2014). The individual and society: challenges of social change. Sofia : s.n., 2014. 307 str. ISBN 978-954-411-151-9. [COBISS. SR -ID 512243298]

[11] Radović Marković, M., Đukanović, B., Marković, D.,Dragojević, A., (2021). Entrepreneurship and Work in the Gig Economy -The Case of the Western Balkans, Routledge, London, United Kingdom, ISBN 9780367725778

[12] Radović Marković, M., Radulović D., Đukanović, B.,(2021).Ekonomski ,pravni i socijalnopsihološki aspekti rada od kuće, izdavač "akademska kinjižarnica Zoran Stojanović", Novi Sad 272 str. ISBN 978-86-7543-396-5

[13] Bennett, T., M. Savage, E.B. Silva, A. Warde, M. Gayo-Cal and D. Wright (2009) Culture, Class, Distinction. London: Routledge

[14] Gali G.,Fakhrutdinova A., Dulmukhametova G., Gilyazova K., Gali I. (2019) Methodical Features of Foreign Language Teaching to Linguistically Gifted Students of Non-Linguistic Specialties: Foreign Experience,, International Review No.3-4/2019, Faculty of Business Economics and Entrepreneurship [16]

\section{Article history:}

Received 25 November 2021

Accepted 17 December 2021 